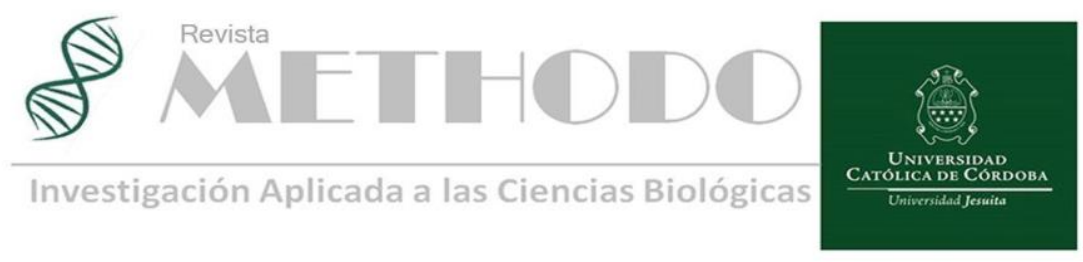

CASO CLINICO Rev. Methodo 2022;7(1):42-44

https://doi.org/10.22529/me.2022.7(1)07

Recibido 20 Sep. 2021 | Aceptado 02 Nov. 2021 |Publicado 05 Ene. 2022

\title{
Hipercalcemia como complicación de hepatocarcinoma
}

\section{Hypercalcemia as a complication of hepatocarcinoma}

\author{
Mercedes Bertello ${ }^{1}$ (D) Pablo Lucero ${ }^{2}$ \\ 1.Universidad Católica de Córdoba, Facultad de Ciencias de la Salud, Clínica Universitaria Reina Fabiola, Servicio de Medicina Interna \\ 2. Clínica Universitaria Reina Fabiola, servicio de medicina Interna \\ Correspondencia: Mercedes Bertello; email: merbertello@gmail.com
}

\section{Resumen}

El carcinoma hepatocelular es el tumor hepático maligno más frecuente. El mismo puede producir, raramente, metástasis óseas líticas o síndromes paraneoplásicos que generan hipercalcemia, disminuyendo la probabilidad de supervivencia de los pacientes.

Se presenta el caso de un paciente con hipercalcemia severa secundaria a un carcinoma hepatocelular.

Palabras claves: Hipercalcemia, carcinoma hepatocelular, metástasis óseas, síndromes paraneoplásicos.

\section{Abstract}

Hepatocellular carcinoma is the most common malignant liver tumor. It can produce, rarely, lytic bone metastases or paraneoplastic syndromes that generate hypercalcemia, reducing the probability of survival of patients.

The case of a patient with severe hypercalcemia secondary to hepatocellular carcinoma is presented.

Keywords: Hypercalcemia, hepatocellular carcinoma, lytic bone metastases, paraneoplastic síndromes.

\section{Introducción}

El carcinoma hepatocelular es el tumor primario de hígado más frecuente, ya que supone el $90 \%$ de los casos. Representa aproximadamente el 7\% de todas las neoplasias. Es la tercera causa de muerte por cáncer y la primera en pacientes con cirrosis $^{1}$. Se asocia a infección por virus hepatitis B, C, alcoholismo e hígado graso no alcohólico. La hipercalcemia es la presencia de un valor de calcio sérico total superior a $10,5 \mathrm{mg} / \mathrm{dl}$, considerándose grave cuando los niveles son superiores a $15 \mathrm{mg} / \mathrm{dl}$, constituyendo una urgencia metabólica ${ }^{2}$.

La prevalencia de hipercalcemia en pacientes con carcinoma hepatocelular es de 5,3\% ${ }^{3}$. La misma puede deberse a metástasis óseas o síndrome paraneoplásico.

\section{Caso clínico}

Varón de 64 años, con diagnóstico de hepatocarcinoma celular en estadio IV (metástasis pulmonares y óseas, osteolíticas en cráneo, maxilar inferior, hombros, clavículas, esternón, arcos costales y cuerpos vertebrales dorsales) fue traído a la institución por familiares que refirieron fluctuación del estado de consciencia con desorientación temporo espacial de 15 días de evolución que se acentuó en las 
últimas 48 horas, asociado a constipación de 10 días.

Al examen físico los signos vitales eran normales. Se encontraba vigil, por momentos respondía órdenes simples, pero con tendencia a la excitación psicomotriz. Las pupilas eran mióticas simétricas e hiporreactivas. Fuerza, tono y trofismo, conservados en los 4 miembros. Esfínteres continentes. Marcha eubásica.

Se realiza un electrocardiograma, donde se constata intervalo QT de 0.32 segundos (valor normal 0.32 a 0.40 segundos).

En el laboratorio presentaba: creatinina 2.6 $\mathrm{mg} / \mathrm{dl}$, urea $190 \mathrm{mg} / \mathrm{dl}$, fosfatasa alcalina 1551 u/I, albúmina $3.77 \mathrm{~g} / \mathrm{dl}$, fosfatemia: $4.8 \mathrm{mg} / \mathrm{dl}$, Calcio iónico $1.75 \mathrm{mmol} / \mathrm{l}$, calcemia $16.2 \mathrm{mg} / \mathrm{dl}$, vitamina $\mathrm{D}$ total $(\mathrm{d} 2+\mathrm{d} 3): 15.26 \mathrm{ng} / \mathrm{ml}$, parathormona (PTH): $8.58 \mathrm{pg} / \mathrm{ml}$ (valor normal: 10-55 pg/ml). Ionograma normal. Antígeno carcinoembrionario (CEA) $1873 \mu \mathrm{g} / \mathrm{L}$ (valor normal: 0 a $2.5 \mu \mathrm{g} / \mathrm{L}$ ). Se realiza una tomografía cerebral, sin contraste, donde no se visualizan lesiones encefálicas.

Se diagnostica síndrome confusional por hipercalcemia severa no PTH dependiente asociado a insuficiencia renal aguda. Se realiza tratamiento con hiperhidratación, pamidronato $90 \mathrm{mg}$ y dexametasona $24 \mathrm{mg} /$ día.

A las 24 horas el valor de calcemia es de 13.3 $\mathrm{mg} / \mathrm{dl}$. En 3 días, normaliza calcemia a $9.6 \mathrm{mg} / \mathrm{dl}$, al igual que su estatus de conciencia. Se indica tratamiento preventivo de hipercalcemia maligna con denosumab. Paciente evoluciona favorablemente y se otorga el alta institucional

\section{Discusión}

La hipercalcemia secundaria a carcinoma hepatocelular es una complicación que puede presentarse del 5,3\% al $8 \%$ según distintas fuentes bibliográficas ${ }^{3-6}$, siendo la misma de escasa presentación ya que la diseminación más conocida del carcinoma hepatocelular es la infiltración portal y pulmonar en un $35 \%$, o en ganglios abdominales en un $20 \%$; y solamente el 5 al $7 \%$ de los casos presentan metástasis óseas ${ }^{4}$. Estas últimas se presentaron en nuestro paciente, y pueden provocar, por lisis óseas, alteraciones neurológicas, cardiovasculares y renales resultantes del aumento de los niveles de calcio en sangre.

La mayoría de las hipercalcemias secundarias a patologías oncológicas se producen en fases avanzadas de la enfermedad y son debidas a 3 mecanismos:

Osteólisis (20-30\%), frecuente en quienes presentan metástasis óseas líticas extensas; Hipercalcemia humoral tumoral (70-80\%), debido a la secreción por parte del tumor de sustancias con actividad hipercalcemiante como PrPTH (péptido relacionado con la hormona paratiroide) como síndrome paraneoplásico o el Factor activador de osteoclastos; y la síntesis ectópica de 1,25-dihidroxivitamina $\mathrm{D}$ descrita en ciertos linfomas y enfermedades granulomatosas ${ }^{5}$.

En nuestro caso se plantearon diferentes causas de hipercalcemia independiente de PTH, como la producción de proteína relacionada con hormona paratiroidea (PrPTH) por el carcinoma hepatocelular como síndrome paraneoplásico, y/o la lisis ósea por las múltiples metástasis. Para obtener un diagnóstico definitivo de la causa de la hipercalcemia se debe dosar PrPTH, el cual no se dispone en nuestro medio.

Castro Camero y Col, de la Universidad de Michigan, reportaron un caso de un paciente con un cuadro clínico severo de hipercalcemia secundaria a carcinoma hepatocelular de curso fulminante, quien consultó por un cuadro confusional, como en nuestro caso, acompañado por dolor abdominal y debilidad generalizada ${ }^{6}$. Similar a nuestro caso, se realizó tomografía de cerebro, con resultado normal por lo cual los autores atribuyeron su cuadro a una causa metabólica.

A diferencia de nuestro caso en cuestión, el paciente cursó evolución tórpida sin poder conocer la presencia o ausencia de metástasis óseas y en el laboratorio se encontró PTHrP elevada, de $39 \mathrm{pg}$. / $\mathrm{ml}$, por lo que se arribó al diagnóstico de hipercalcemia humoral tumoral ${ }^{6}$

\section{Bibliografía}

1. Bosch FX, Ribes J, Díaz M, Cléries R. Primary liver cancer: worldwide incidence and trends. Gastroenterology. 2004;127: S5-S16.

2. A. Muñoz Garacha, A. García Martín y M. Muñoz Torres. Alteraciones del metabolismo fosfocálcico.Hipercalcemia.

Hiperparatiroidismo. Medicine. 2016;12(16):893-9.

3. Ahmed Maarouf, Mustapha Adham, Jean Yves Scoazec, Christian Partensky, J. Mixed hepato/cholangiocarcinoma with paraneoplastic hypercalcemia. Hepatobiliary Pancreat Surg (2008) 15:224-227. 
4. N. Sanz Arevalillo, F. Bolado Concejo, C. Cardona Castellá, J. J. Giné Gala, M. Llobera Serentill, Metástasis ósea como primera manifestación de un hepatocarcinoma. An. Med. Interna (Madrid) vol.21 no.4 abr. 2004.

5. A. Muñoz Garacha, A. García Martín y M. Muñoz Torres. Alteraciones del metabolismo fosfocálcico.Hipercalcemia. Hiperparatiroidismo.

Medicine. 2016;12(16):893-9.

6. Pamela Castro-Camero, Bumsoo Park, Amit Gupta, Raghavendra Vemulapalli, and Maria Shreve. A Case of Humoral Hypercalcemia of Malignancy Secondary to Hepatocellular Carcinoma with Fulminant Clinical Course. Spartan Medical Research Journal 2019.

\section{(c)(1)(9)

